\title{
Seasonal and interannual variability of physical and biological dynamics at the shelfbreak front of the Middle Atlantic Bight: nutrient supply mechanisms
}

\author{
R. He ${ }^{1}$, K. Chen ${ }^{1}$, K. Fennel ${ }^{2}$, G. G. Gawarkiewicz ${ }^{3}$, and D. J. McGillicuddy Jr ${ }^{4}$ \\ ${ }^{1}$ Department of Marine, Earth and Atmospheric Sciences, North Carolina State University, USA \\ ${ }^{2}$ Department of Oceanography, Dalhousie University, Canada \\ ${ }^{3}$ Department of Physical Oceanography, Woods Hole Oceanographic Institution, USA \\ ${ }^{4}$ Department of Applied Ocean Physics and Engineering, Woods Hole Oceanographic Institution, USA
}

Received: 1 February 2011 - Published in Biogeosciences Discuss.: 21 February 2011

Revised: 3 October 2011 - Accepted: 11 October 2011 - Published: 20 October 2011

\begin{abstract}
A high-resolution, 3-dimensional coupled biophysical model is used to simulate ocean circulation and ecosystem variations at the shelfbreak front of the Middle Atlantic Bight (MAB). Favorable comparisons between satellite observations and model hindcast solutions from January 2004 to November 2007 indicate the model has intrinsic skills in resolving fundamental physical and biological dynamics at the MAB shelfbreak. Seasonal and interannual variability of ocean physical and biological states and their driving mechanisms are further analyzed. The domain-wide upper water column nutrient content is found to peak in late winter-early spring. Phytoplankton spring bloom starts 1-2 months later, followed by zooplankton bloom in early summer. Our analysis shows the variability of shelfbreak nutrient supply is controlled by local mixing that deepens the mixed layer and injects deep ocean nutrients into the upper water column and alongshore nutrient transport by the shelfbreak jet and associated currents. Nutrient vertical advection associated with the shelfbreak bottom boundary layer convergence is another significant contributor. Spring mean nutrient budget diagnostics along the Nantucket transect are compared between nutrient rich 2004 and nutrient poor 2007. Physical advection and diffusion play the major role in determining strong interannual variations in shelfbreak nutrient content. The biological (source minus sink) term is very similar between these two years.
\end{abstract}

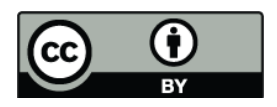

Correspondence to: $\mathrm{R}$. He (rhe@ncsu.edu)

\section{Introduction}

The Middle Atlantic Bight (MAB) shelfbreak region contains a sharp front that separates the cold, fresh water on the shelf from warmer, more saline water in the slope sea. Associated with the front is a narrow shelfbreak jet, which is a part of the large-scale buoyancy driven coastal current originating from the Labrador Sea (Chapman and Beardsley, 1989; Loder et al., 1998). The MAB shelfbreak front and jet exert a strong influence on the cross-shelf exchanges of mass, heat, freshwater, and nutrients, which further control the characteristics of physical and biological dynamics at the shelfbreak.

In situ and satellite observations often show higher levels of chlorophyll within the MAB frontal region, also known as the shelfbreak pigment maximum (Marra et al., 1982; Ryan et al., 1999a, b, 2001). This locally enhanced productivity provides energy to upper trophic level predators. As a result, fishes and marine mammals often aggregate in the shelfbreak front (Podestá et al., 1993; Waring et al., 2001). Several mechanisms are proposed to explain the shelfbreak frontal biomass enhancement. The secondary circulation in the bottom boundary layer (Gawarkiewicz and Chapman, 1992; Houghton, 1997; Houghton and Visbeck, 1998; Barth et al., 1998; Gawarkiewicz et al., 2010) has been considered as one possible process for delivering both regenerated nutrients from benthic processes over the shelf as well as deepocean nutrients to the euphotic zone, thus boosting primary production. The lateral transport of nutrients and plankton from the Georges Bank region is considered another key process. It is known that upstream of the MAB shelfbreak, tidal

Published by Copernicus Publications on behalf of the European Geosciences Union. 
pumping on the Georges Bank constantly injects nutrients into the upper water column (e.g., Townsend and Thomas, 2002). While some nutrients are consumed locally, a portion can be transported downstream to the MAB.

Most earlier studies on the MAB shelfbreak circulation and ecosystem dynamics are based on either synoptic in situ surveys (e.g., Gawarkiewicz et al., 2001; Hales et al., 2009) or satellite imagery (e.g., Ryan et al., 2001; He et al., 2010). While having provided many valuable insights into how the shelfbreak system works, in situ observations are limited by both temporal and spatial coverage, whereas remote sensing is compromised by clouds and limited by its inability to measure the subsurface (e.g., Miles et al., 2009; He et al., 2010).

In this study, we utilize a coupled biophysical model to study MAB shelfbreak physical and biological dynamics and their associated seasonal and interannual variability. The hydrodynamics is simulated by a recently developed 3-dimensional, high resolution MAB shelfbreak circulation model described by Chen and He (2010), while the ecosystem dynamics is modeled by the biological model described in Lima and Doney (2004) and Lehmann et al. (2009). We performed a multi-year coupled model hindcast spanning from 2004 to 2007. The resulting time and space continuous physical and biological fields are used for several detailed process analyses. In Sect. 2 we give a brief description of both physical and biological models. Model validation against satellite observations is presented in Sect. 3. Causes of temporal and spatial variability of physical, biological and nutrient fields are discussed in Sect. 4, followed by summary and conclusions in Sect. 5.

\section{Methods}

\subsection{The circulation model}

The MAB shelfbreak circulation model was configured based on the Regional Ocean Modeling System (ROMS, Haidvogel et al., 2008; Shchepetkin and McWilliams, 2005). The model domain encompasses the MAB shelfbreak offshore of Nantucket Shoals in the northeast and Hudson Canyon in the southwest (Fig. 1). Within the domain, the water depth ranges from 30 to $3000 \mathrm{~m}$. The horizontal resolution of the model is $1 \mathrm{~km}$. 36 terrain-following vertical levels are used in the water column with higher resolution near the surface and bottom to better resolve both ocean surface and bottom boundary layers. The minimum (maximum) model vertical spacing is $0.8 \mathrm{~m}(211 \mathrm{~m})$ in the boundary layer (the mid-water column).

The MAB shelfbreak ROMS is one-way nested inside a regional-scale Middle Atlantic Bight and Gulf of Maine ROMS (hereafter MABGOM ROMS described and validated by $\mathrm{He}$ and Chen, submitted), which itself is nested in the global HyCOM circulation model. Along the 4 open boundaries of the shelfbreak ROMS, we use the method of Flather

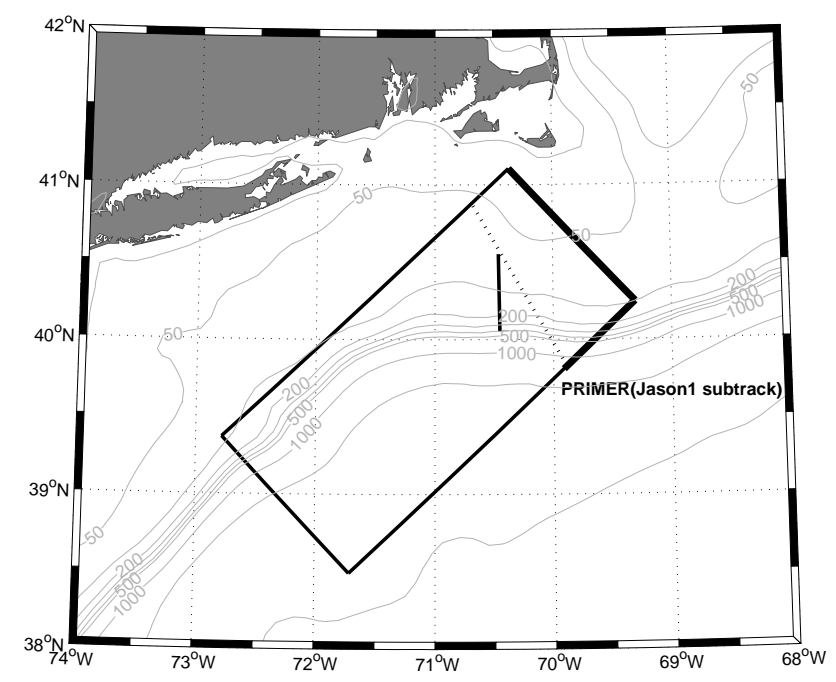

Fig. 1. The shelfbreak model domain (box) and the location of Nantucket transect discussed in the following sections (solid line). Also shown is a satellite (Jason1) sub-track (dotted line). The thick line along the northeastern boundary defines the location of the upstream nutrient input calculation. Local isobaths are also shown in light gray.

(1976) to specify the free-surface and depth-averaged velocity with MABGOM ROMS solutions plus $\mathrm{M}_{2}$ tidal harmonics from an ADCIRC tidal simulation of the western Atlantic (Luettich et al., 1992). For boundary temperature, salinity, and baroclinic velocity, an Orlanski-type radiation condition (Marchesiello et al., 2001) is applied. Surface momentum and buoyancy forcing comes from a standard bulk flux calculation (Fairall et al., 2003) using the NOAA NCEP North American Regional Reanalysis (NARR) archive that includes air temperature, relative humidity, air pressure, short wave radiation, long wave radiation, cloud coverage, precipitation and surface wind speed. We applied the method of Mellor and Yamada (1982) to compute vertical turbulent mixing, as well as the quadratic drag formulation for the bottom friction specification.

\section{The biological model}

The biological model of Lehmann et al. (2009), which is based on the model of Lima and Doney (2004), is used to simulate the dynamics of picophytoplankton, diatoms, zooplankton, large detritus, small detritus, and the inorganic nutrients: nitrate and ammonium in the MABGOM domain. The nitrogen and carbon content of phytoplankton, zooplankton and detritus are tracked in the model. Chlorophyll content of the picophytoplankton and diatom groups are variable. Phytoplankton grow as a function of light, inorganic nitrogen concentration and temperature. The intracellular ratios of nitrogen, carbon and chlorophyll for phytoplankton 
are based on Geider et al. (1998) but modified to include both nitrate and ammonium (Lima and Doney, 2004). In addition to being grazed, small and large phytoplankton are converted into small and large detritus, respectively, through a combination of linear and quadratic loss terms. A combination of linear and quadratic terms also describes the losses from zooplankton to detritus. Decomposition of detritus to ammonium by heterotrophic bacteria is parameterized using a linear remineralization rate. Large detritus sinks at a rate of $10 \mathrm{~m} \mathrm{~d}^{-1}$, while small detritus and all other biological variables do not sink. For simplicity and model stability, the diverse zooplankton population is parameterized in a single zooplankton compartment with an S-shaped grazing function (Holling-type III) and a quadratic mortality term. In Lehmann et al. (2009) implementation, silicate was not included and hence the diatom group was interpreted more generally as large phytoplankton. Interested reader is referred to Lima and Doney (2004) and Lehmann et al. (2009) for more detailed biological equations and parameterizations as well as differences between two implementations.

The shelfbreak biological model is embedded in its MABGOM counterpart in the same fashion as the one-way circulation downscaling described above. Its initial and boundary conditions were derived from the MABGOM biological simulation of Lehmann et al. (2009), which itself is nested inside a US east coast model of Fennel et al. (2008) and initialized with a blended nutrient dataset combining WOA climatology and regional observations. The coupled simulation was initialized on 1 December 2003 and run continuously to 19 November 2007. For model validation and analyses described in the following sections, we focus on the period of January 2004 to November 2007.

\section{Model-Data comparisons}

Extensive comparisons between observed and simulated shelfbreak hydrodynamics have been presented in Chen and $\mathrm{He}$ (2010). Validations show that the MAB shelfbreak ROMS has decent skill in resolving synoptic, seasonal and interannual variability of the shelfbreak circulation, lending confidence that the biological simulation is couched in a realistic physical environment.

Satellite ocean color observations provide crucial information for validating biological model solutions. In this case, we used Aqua MODIS (Moderate Resolution Imaging Spectroradiometer) monthly mean chlorophyll data. This $4 \mathrm{~km}$ resolution MODIS dataset was mapped onto the shelfbreak model domain (Fig. 1). The time series of domain-averaged chlorophyll concentration from both MODIS and our model simulation were compared to examine how well the model resolves seasonal and interannual variations.

The MODIS observations show that maximum surface chlorophyll concentration (ca. $1.5 \mathrm{mg} \mathrm{m}^{-3}$ ) occur from March to May (Fig. 2) during the spring bloom. The surface

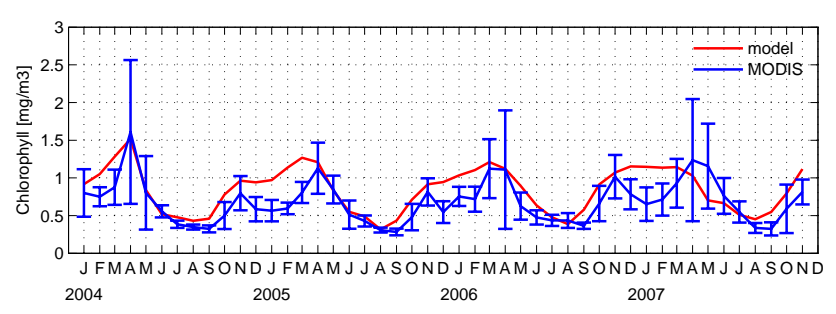

Fig. 2. Monthly domain-averaged surface chlorophyll from the shelfbreak model (red) and Aqua-MODIS data (blue, with one standard deviation). The model data are taken from the top vertical layer of the model.

chlorophyll concentration then declines to its annual minimum in summer (July to September) as the result of zooplankton grazing, and nutrient depletion associated with the development of summer stratification e.g., Walsh et al., 1987; Sosik et al., 2001) In the fall, increased mixing due to storms and convective cooling break down the thermal stratification. The consequent introduction of deep water nutrients into the euphotic zone stimulates a fall bloom that is discernable in October-November (O'Reilly and Zetlin, 1998; Yoder et al., 2002). The maximum chlorophyll concentration in fall is about a half of the spring peak value. Simulated chlorophyll fields closely resemble these observations (Fig. 2). Indeed, the model captures the chlorophyll seasonal evolution well, with values generally falling within 1 standard deviation of their observational counterparts throughout almost the entire year. A discrepancy is seen in the winter when the model overestimates chlorophyll concentration. This is likely due to excessive winter mixing produced by the turbulence closure scheme (He and Chen, 2011), an aspect we seek to improve in a future effort.

A more robust statistical skill assessment of the temporal evolution of the domain-averaged surface chlorophyll is shown by year in the form of a Taylor diagram (Taylor, 2001), where correlation coefficients, centered root mean square differences (RMSD) between observed and simulated domain-averaged chlorophyll concentration, and normalized standard deviations are all presented in a single plot (Fig. 3). Except for 2007, the correlation coefficients between the model and data are all larger than 0.5 and all centered RMSD are less than one. The standard deviation of the simulated 2005 time series of surface chlorophyll concentration is close to that of the observations, while for other years, the values are generally smaller indicating that the model slightly underestimates observed temporal variations in the surface chlorophyll field

Model skill is further investigated by comparing observed and simulated spatial patterns in their respective seasonal means (Fig. 4). Both are obtained by averaging over a 4-year period (2004-2007). In spring, the phytoplankton bloom spreads over the entire shelfbreak domain. Elevated chlorophyll concentrations are found on Nantucket Shoals, 


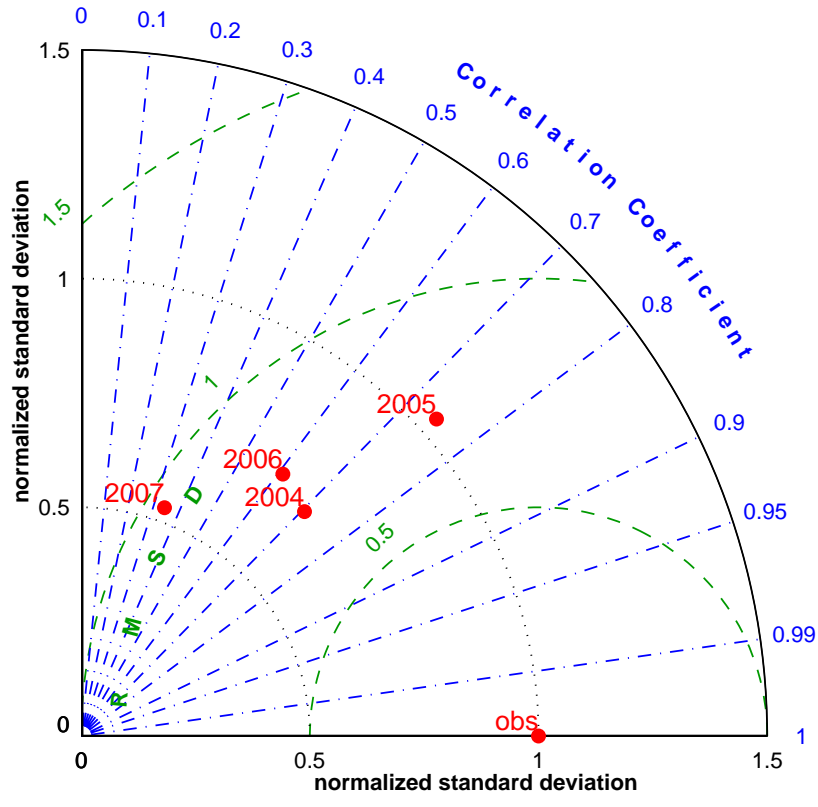

Fig. 3. Taylor Diagram for domain-averaged surface chlorophyll concentrations from 2004 to 2007. Radial distance represents the ratio of simulated to observed standard deviations, and azimuthal angle represents model-data correlation. Green arcs represent centered root mean square difference between model and data.

probably due to nutrient supply induced by strong tidal mixing (He and Wilkin, 2006). The model shows an elevated chlorophyll concentration at the shelfbreak; while this feature is less obvious in the relatively coarse resolution $(4 \mathrm{~km})$ seasonal mean satellite image, it is consistent with previous studies (e.g., Ryan et al., 1999a) showing the occurrence of shelfbreak chlorophyll enhancement during the spring season. In the summer, there is a minimum of chlorophyll at the surface in the entire study domain except the Nantucket Shoals region. In the fall, the breakdown of stratification allows deep-ocean nutrients to reappear in the upper water column, stimulating a region-wide fall bloom that leads to higher chlorophyll concentrations relative to summer conditions. In winter, observations show surface chlorophyll concentrations decline again compared to the fall. The decline is associated with both light and nutrient limitation. These comparisons of seasonal maps show that the model is generally able to reproduce the seasonal evolution and spatial characteristics of the MAB shelfbreak chlorophyll fields.

Together, all comparisons (Figs. 2-4) indicate that our shelfbreak biological model has some intrinsic skill in resolving the spatiotemporal variations of surface chlorophyll in the MAB shelfbreak region, providing us the confidence to use a 4-year hindcast to further characterize the physical and biological dynamics at the MAB shelfbreak.
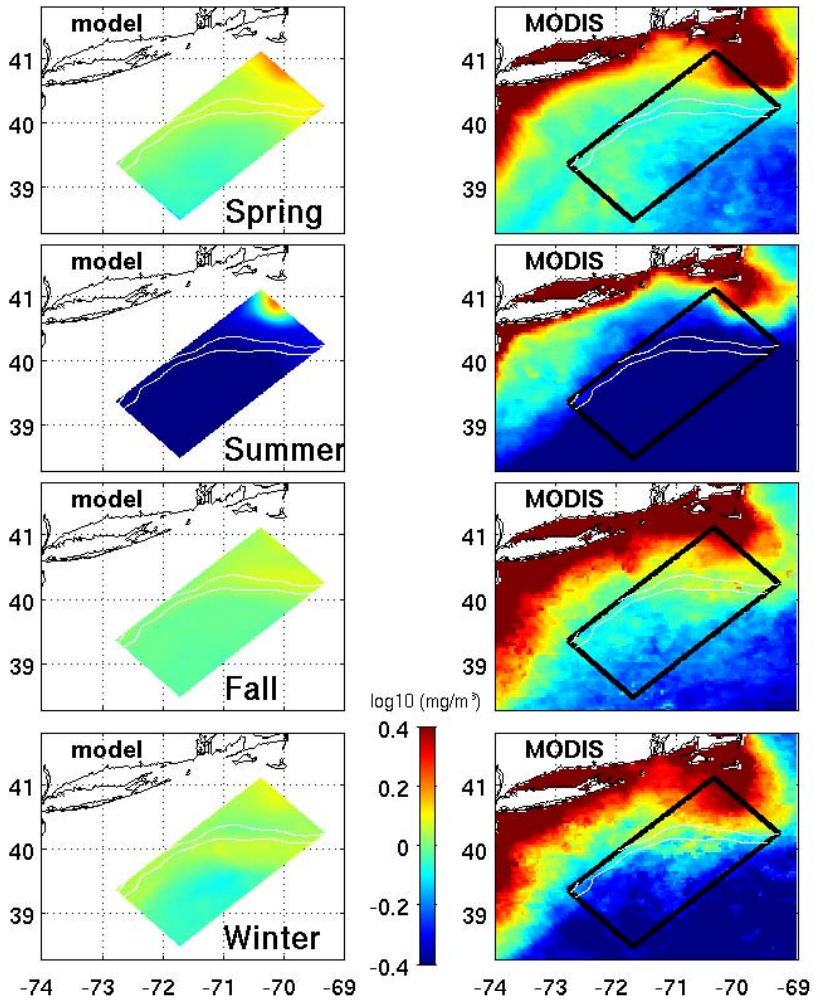

Fig. 4. Seasonal surface chlorophyll comparisons based on simulated and observed 4-year mean results. Shown in the left column are model results (taken from the top layer of model) and those in the right column are MODIS observed results, with the model domain overlaid (black box). 100 and $200 \mathrm{~m}$ isobaths are also shown (white curves).

\section{Discussion}

\subsection{Seasonal and interannual variability of biological dynamics}

We begin by focusing on the variations of simulated nutrient (nitrate and ammonium), phytoplankton (picophytoplankton and diatom) and zooplankton concentrations in the upper water column. For this analysis, all these fields are vertically averaged over the upper $50 \mathrm{~m}$ (for regions where local water depths are less than $50 \mathrm{~m}$, the entire water column is used in averaging). Subsequently, they are also averaged over the entire model domain. The reason for choosing $0-50 \mathrm{~m}$ average quantities as diagnostics is that $50 \mathrm{~m}$ is generally the base of euphotic zone (Hales et al., 2009; Houghton et al., 2009) so that biological components in the upper $50 \mathrm{~m}$ largely represent the major characteristics of the ecosystem.

\subsubsection{Seasonal variability}

Clear seasonality in the upper water column is seen in all variables except ammonium (Fig. 5). The highest nitrate 

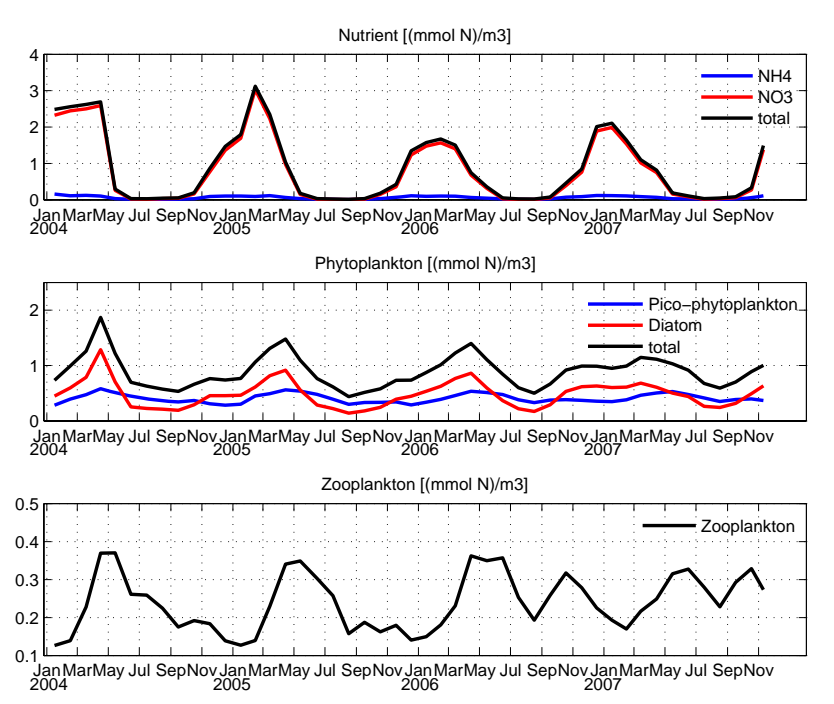

Fig. 5. Monthly mean time series of nutrient, phytoplankton and zooplankton components simulated by the model.

concentration occurs in late winter and early spring. The annual maximum nitrate concentration varies from 1.5 to $3 \mathrm{mmol} \mathrm{m}^{-3}$ over the study period. While the nitrate nutrient is abundant, phytoplankton growth is apparently inhibited by light limitation. In fact, the phytoplankton bloom does not start until the following spring season when both sufficient light and nutrients are present. Maximum phytoplankton concentrations are seen from March to May, approximately 1-2 months after the peaks in nutrient concentration. Among the phytoplankton groups, picophytoplankton show less seasonal variability with an averaged concentration of roughly $0.5 \mathrm{mmol} \mathrm{N} \mathrm{m}^{-3}$. The diatoms show a more pronounced seasonal cycle. Their peak values are around $1.5 \mathrm{mmol} \mathrm{N} \mathrm{m}^{-3}$, thus contributing more to the total phytoplankton variability. Zooplankton blooms begin in May-June, lagging phytoplankton blooms by approximately one month. The yearly maximum concentrations range from 0.3 to $0.4 \mathrm{mmol} \mathrm{N} \mathrm{m}^{-3}$.

In the summer, nutrients are depleted in the upper water column. Consequently, both phytoplankton and zooplankton concentrations reach their annual minima. Stronger mixing events in the fall allow some regenerated deep water nutrients to enter the euphotic zone, which stimulate a weaker phytoplankton fall bloom, followed by a more discernable zooplankton bloom in November. Indeed, the seasonal evolution of nutrients, phytoplankton and zooplankton underscore the fact that the availability of nutrients influences the timing and distribution of plankton blooms at the MAB shelfbreak.

\subsubsection{Interannual variability}

We next focus on the interannual variability of nutrient budgets (Fig. 6). In 2004 and 2005 the overall spring nutrient concentration (ca. 2 to $3 \mathrm{mmol} \mathrm{N} \mathrm{m}^{-3}$ ) is twice that in 2006 and 2007 (ca. 1 to $2 \mathrm{mmol} \mathrm{N} \mathrm{m}^{-3}$ ). As a result, the
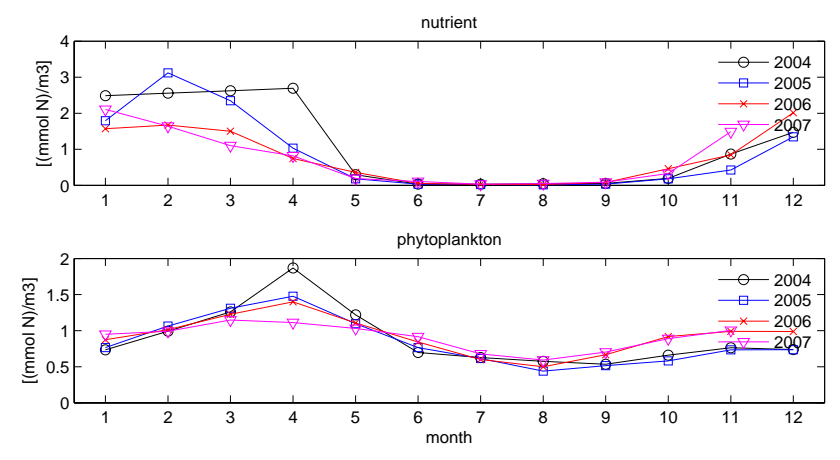

Fig. 6. Inter-annual evolution of domain-averaged nutrient concentration (upper panel) and phytoplankton concentration (lower panel) at the MAB shelfbreak.

phytoplankton spring bloom is strongest in 2004 and weakest in 2007.

Temporally averaged nutrient fields during late winter and early spring (February-April) of each year allow quantification of interannual nutrient variability with respect to its 4year (2004-2007) mean. The mean nutrient pattern is characterized by higher concentrations (ca. $3 \mathrm{mmol} \mathrm{N} \mathrm{m}^{-3}$ ) in the northeastern corner of our shelfbreak domain (Fig. 7, top left panel). Combined with existing knowledge of regional mean circulation (e.g., Lentz, 2008), this pattern indicates a nutrient input from upstream coastal areas (e.g., Georges Bank). The across-shelf nutrient field along the Nantucket transect (Fig. 7, top right panel) further indicates that nutrient concentration increases with depth, and that there is a "nutrient pool" shoreward of the shelfbreak. These "mean" states are comparable with in situ synoptic observations collected in the same region (Hales et al., 2009; Gawarkiewicz et al., 2010).

With respect to mean nutrient conditions, 2004 is characterized as a positive anomaly year. Nutrient contents over the entire shelf (both surface and sub-surface) are higher by ca. $1 \mathrm{mmol} \mathrm{N} \mathrm{m}^{-3}$. A similar situation is observed in 2005 , although the higher anomalies are primarily located seaward of the shelfbreak. In contrast, 2006 and 2007 are characterized as negative anomaly years. For most areas of the shelfbreak domain, nutrient content in these two years are ca. $1 \mathrm{mmol} \mathrm{N} \mathrm{m}^{-3}$ less than the mean conditions.

\subsubsection{Dominant modes of variability}

To quantify the dominant modes of nutrient and plankton variability in the upper water column $(50 \mathrm{~m})$, and their intrinsic linkages, we removed their temporal means and applied Empirical Orthogonal Function (EOF) analysis to their residuals. Temporal mean phytoplankton and zooplankton fields resemble the mean nutrient distribution (Fig. 8, upper panels). For all three variables, high concentrations occur near the upstream (northeastern) boundary of the shelfbreak domain. Maximum values for both phytoplankton and 


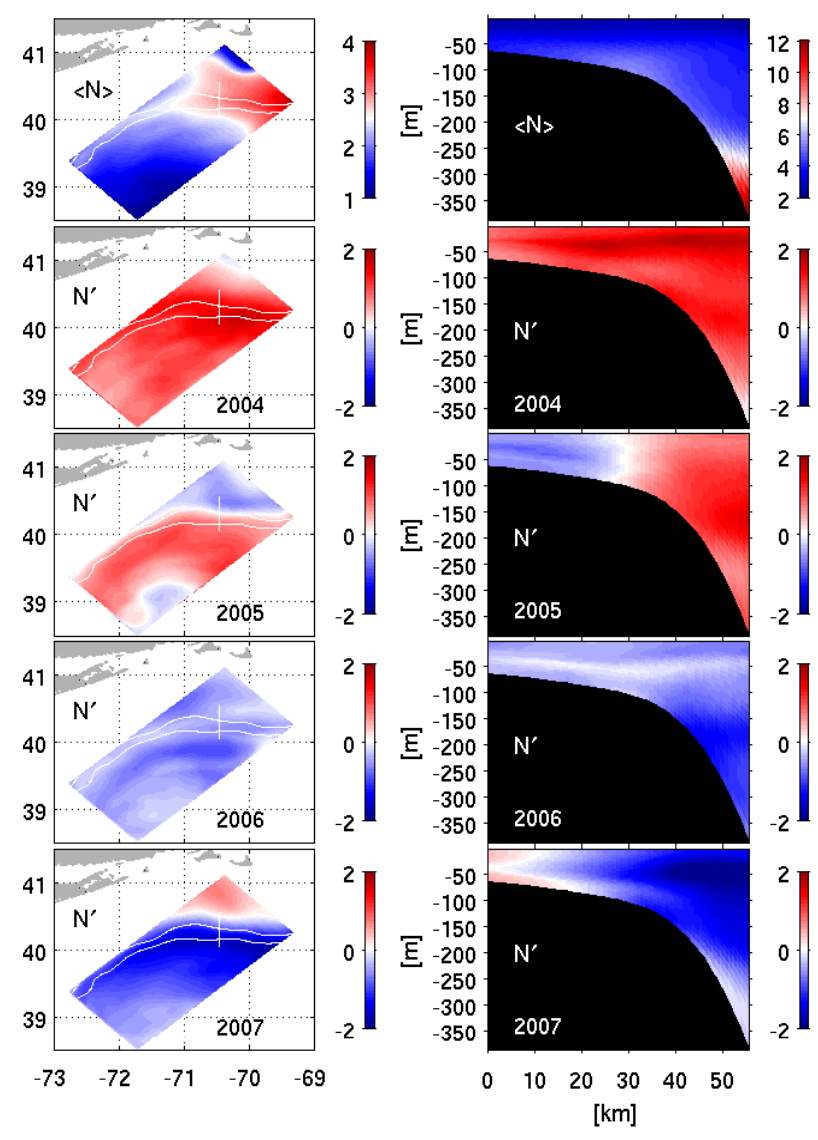

Fig. 7. Inter-annual variability of nutrient concentration. Shown in the left from top to bottom are the spring mean upper water column (upper $50 \mathrm{~m}$ average) nutrient field averaged over 2004-2007, and the corresponding nutrient anomaly fields in springs 2004 through 2007 relative to their 4-year mean. Shown in the right from top to bottom are the spring mean nutrient field along the Nantucket transect, and the corresponding across-shelf nutrient anomaly fields in springs 2004 through 2007 relative to their 4-year mean. Note different colorbars are used in the top panel. Also shown in the left panels are the location of the Nantucket transect, and 100 and $200 \mathrm{~m}$ isobaths (white curves). All units are $(\mathrm{mmolN}) \mathrm{m}^{-3}$.

zooplankton are located in the northern corner of the domain (Nantucket shoals), shoreward of the nutrient maxima.

The first EOF mode of the surface nutrient field accounts for $87 \%$ of the variance, highlighting an apparent shelfbreak nutrient enhancement pattern. Its corresponding first principal component (PC1) shows the shelfbreak surface nutrient content reaches its peak value in the late winter and early spring (Feb-Apr), and then becomes depleted in the summer. The first EOF modes of phytoplankton and zooplankton account for $82 \%$ and $73 \%$ of the variance, respectively. For phytoplankton, the largest EOF values are located further downstream along the shelfbreak, whereas for zooplankton, the largest EOF values are nearly collocated with those of the nutrient EOF. Such differences in spatial distribution

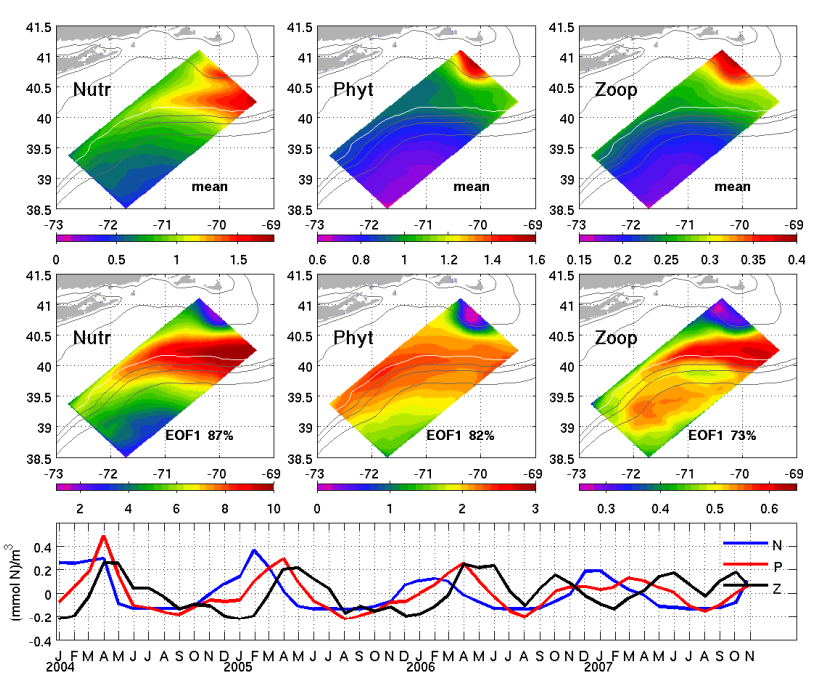

Fig. 8. EOF analyses of upper water column (averaged over the upper $50 \mathrm{~m}$ ) nutrient, phytoplankton and zooplankton fields. Mean fields are shown in the top panels (units: $(\mathrm{mmolN}) \mathrm{m}^{-3}$ ), the first EOF modes with the variance they account for are shown in the middle panels and their corresponding 1st principle components are shown in the bottom panels. Also shown are isobaths (gray curves) with $200 \mathrm{~m}$ isobath highlighted in white.

are presumably a result of the zooplankton grazing on phytoplankton.

Together, the PC1s of surface nutrient, phytoplankton and zooplankton highlight some interesting phase-locked patterns. Except for spring 2004, the nutrient variations generally lead phytoplankton variations by ca. 2 months, which in turn leads zooplankton variations by ca. 1 month. Consistent with Sect. 4.1.a, the EOF analysis indicates that shelfbreak plankton variation is influenced by the timing and distribution of nutrient supply. We note the second EOF modes of nutrient, phytoplankton and zooplankton representing other dynamical processes, account for only $6 \%, 7 \%$, and $12 \%$ of their respective variances.

A similar EOF analysis (Fig. 9) was performed on acrossshelf nutrient, phytoplankton and zooplankton distributions along the Nantucket transect (location in Fig. 1). The temporal mean nutrient field shows the nutricline is at about $50 \mathrm{~m}$, with waters shallower than $50 \mathrm{~m}$ largely depleted of nutrients. This pattern is consistent with recent nutrient observations taken in the same area (Gawarkiewicz et al., 2010). The mean states of phytoplankton and zooplankton are similar in their across-shelf distribution. As a result of light limitation, phytoplankton accumulate mostly in the upper $100 \mathrm{~m}$, as do their predators zooplankton.

The first EOF mode of cross-shelf nutrient residual (after temporal mean removed) accounts for $58 \%$ of its variance. The largest variation is located on the mid-shelf, centered at the $80-100 \mathrm{~m}$ isobath. This feature is collocated with the MAB "cold pool" (Beardsley and Flagg, 1976; Houghton et 


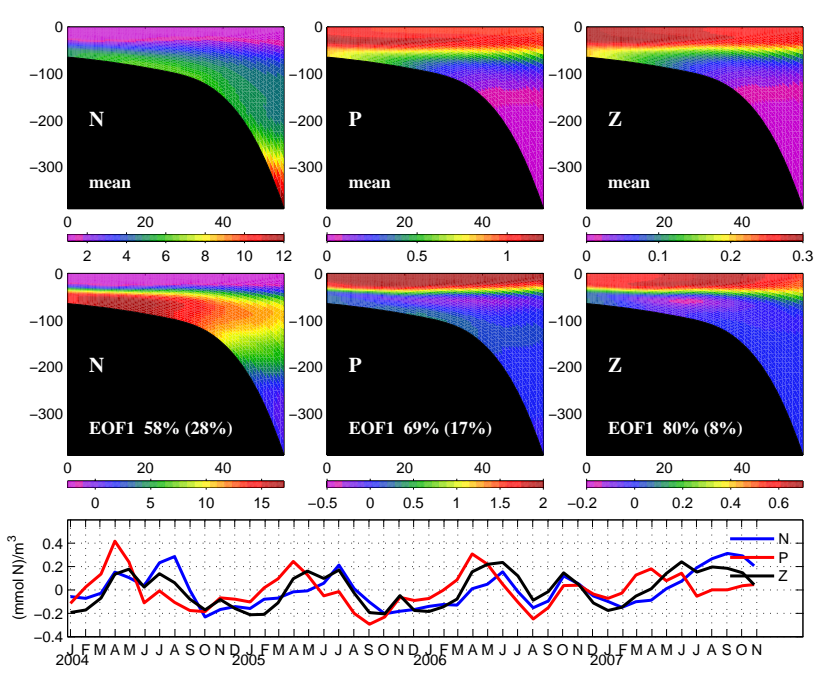

Fig. 9. EOF analyses of nutrient, phytoplankton and zooplankton along the Nantucket transect. Their temporal mean fields are shown on the top panels(units: $(\mathrm{mmolN}) \mathrm{m}^{-3}$ ), the first EOF modes are shown in the middle panel with the variance they account for (also shown in the brackets are percentages of 2 nd EOF mode variance) and the corresponding 1st principle components are shown at the bottom panels.

al., 1982) and the shoreward edge of the mean position of the foot of shelfbreak front (e.g., Linder and Gawarkiewicz, 1998). Earlier studies suggested high levels of nutrient regeneration (Rowe et al., 1975; Rowe et al., 1977; Harrison et al., 1983) in this area. This is supported by time series of PC1 for simulated nutrient and plankton, insofar as nutrient anomalies peak after phytoplankton and zooplankton anomalies peak. The first EOFs of phytoplankton and zooplankton explain $69 \%$ and $80 \%$ of their variances, respectively, both showing the largest variations in the upper water column. For both phytoplankton and zooplankton EOFs, their subsurface variations are slightly out-of-phase (i.e., having opposite signs) from their upper water column counterparts.

\subsection{Physical control on nutrient delivery}

Because the nutrient supply appears to be a central driver of MAB shelfbreak plankton dynamics, the exact mechanisms by which the shelfbreak circulation affects nutrient delivery are crucial for understanding shelfbreak ecosystem dynamics and its associated interannual variability.

We used the upper $50 \mathrm{~m}$ nutrient concentration within the domain as an indicator of nutrient content. The nutrient flux across the northeastern boundary of the model domain was calculated to represent the upstream nutrient input. The variability of monthly mean nutrient content at the MAB shelfbreak is found to be well correlated with the monthly mean upstream nutrient influx (Fig. 10). The correlation coefficient between the two normalized time series is 0.92 (significant

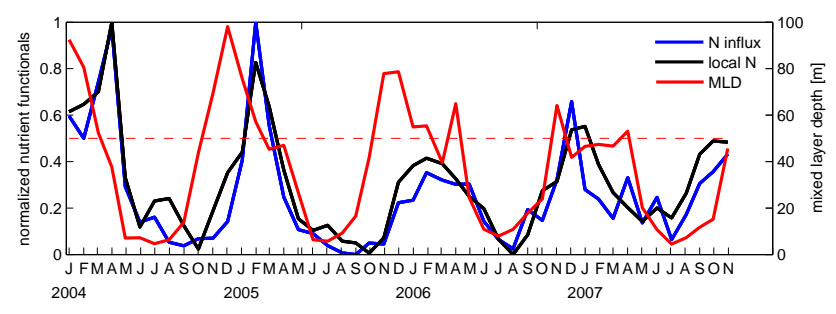

Fig. 10. Monthly means of domain-averaged upper $50 \mathrm{~m}$ nutrient concentration (black line), the upstream nutrient influx (blue line), and the surface mixed layer depth (red line) from 2004 to 2007. Also shown in the dashed red line is $50 \mathrm{~m}$ as a reference depth for MLD. Both $\mathrm{N}$-influx and local $\mathrm{N}$ time series are normalized, whereas the domain- averaged, monthly mean MLD is not and has unit of meter.

at the $95 \%$ confidence level). We note the nutrient content peaks in a time window from November through April. The cause for this feature has both atmospheric and oceanic origins. On one hand, stronger local wind forcing in winter and spring deepens the mixed layer, making more deepocean nutrient available to the upper water column. On the other hand, the shelfbreak jet reaches its highest intensity in spring (Linder et al., 2004; Chen and He, 2010), maximizing the upstream nutrient influx into the MAB shelfbreak area. Taking $0.25 \mathrm{~ms}^{-1}$ as the mean shelfbreak jet speed in spring, it would take it about a week for a fluid parcel in the jet to traverse the shelfbreak domain under study. Because monthly values were used in Fig. 10, such a time lag between local upper water-column $\mathrm{N}$ content and $\mathrm{N}$-influx from the shelfbreak jet is not discernable. However, inflow velocities are much weaker both seaward and landward of the shelfbreak jet, thereby yielding much longer residence time of such fluid. The lack of a temporal lag between upstream nutrient input and the domain-averaged inventory may also reflect the impact of vertical mixing on upper ocean nutrient content. Indeed, time periods of increasing (decreasing) nutrient inventory in the upper $50 \mathrm{~m}$ coincide with time periods of mixed layer depths deeper (shallower) than $50 \mathrm{~m}$ (Fig. 10). Moreover, interannual variations in nutrient content are correlated with mixed layer depth: deeper mixed layers in 2004 and 2005 are associated with larger inventories of nutrients than 2006 and 2007. Covariance between upstream nutrient input and the domain-averaged nutrient content can be explained by the same locally-forced nutrient input pertaining to the outer MABGOM domain used to specify the boundary conditions for the shelfbreak model.

The bottom boundary layer (BBL) convergence associated with the shelfbreak secondary circulation can be used to indicate the intensity of near bottom vertical advection (Chapman and Lentz, 1994; Pickart, 2000; Linder et al., 2004). To confirm the relationship between the BBL convergence $\left(\nabla \cdot V_{\text {bottom }}\right)$ and upper ocean nutrient content, we computed their temporal correlation coefficients point-by-point over 


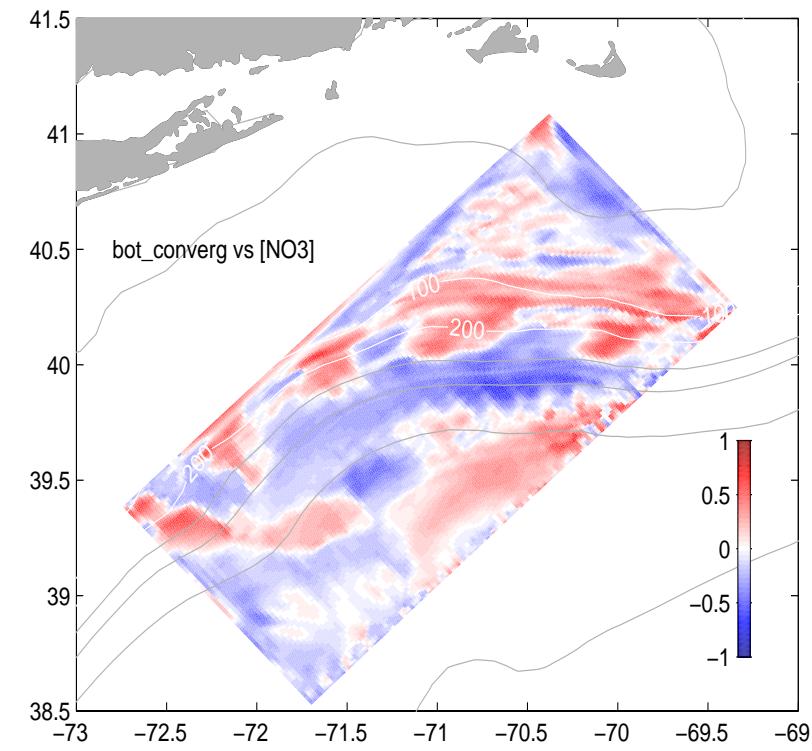

Fig. 11. Spatial correlations between the bottom convergence and NO3 concentration in the upper $50 \mathrm{~m}$. Also shown are isobaths (gray curves) with 100 and $200 \mathrm{~m}$ isobaths highlighted in white.

the entire model domain. The resulting map (Fig. 11) reveals high positive correlation $(r>0.7$ at $95 \%$ confidence level) along the shelfbreak, suggesting that the upper ocean nutrient content is affected by BBL convergence.

Assuming the upstream nutrient concentration stays the same, the nutrient flux supplied by the shelfbreak jet is proportional to its strength, which we can quantify by means of the total kinetic energy $\left(\mathrm{TKE}=\left(u^{2}+v^{2}\right) / 2\right)$. The 4year February-April mean of depth-averaged TKE $(<$ TKE $>$ Fig. 12, top left panel) clearly depicts the shelfbreak jet structure. The 4-year mean seasonal alongshore velocity $<\mathrm{U}\rangle$ at the Nantucket transect (Fig. 12, top right panel) shows that the core of the shelfbreak jet extends to $10-20 \mathrm{~m}$ below the surface with a maximum speed of $0.25 \mathrm{~ms}^{-1}$. Interannual variability (Fig. 12, all other panels) can be gleaned from anomalies (TKE' and $U^{\prime}$ ) of individual spring in each year relative to their 4-year mean seasonal $<$ TKE $>$ and 4 year mean seasonal alongshore velocity $<\mathrm{U}>$ fields. We see spring 2004 in particular is characterized by a much stronger shelfbreak jet and higher TKE (i.e., the largest positive anomalies). In contrast, spring 2007 has the weakest jet and much lower TKE over the entire shelf (i.e., the largest negative anomalies).

Earlier studies have shown that the MAB shelfbreak jet is primarily buoyancy-driven with its interannual variability controlled by large scale hydrography (e.g., Chapman, 1986; Chapman and Beardsley, 1989; Loder et al, 1998; Gawarkiewicz and Chapman, 1992; Chapman and Lentz, 1994; Chapman, 2000). Simulated hydrographic conditions (not shown) over the 4-year hindcast period reveal shelf

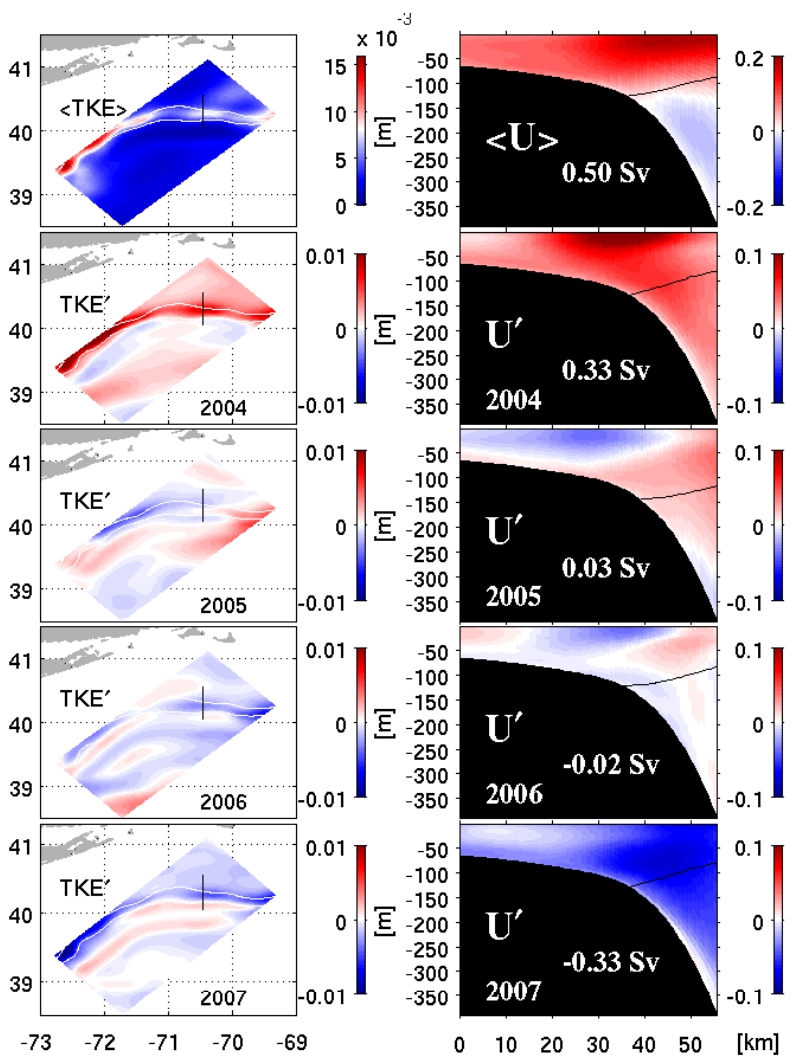

Fig. 12. Inter-annual variability of total kinetic energy (TKE: left column, in unit of $\mathrm{m}^{2} \mathrm{~s}^{-2}$ ) and shelfbreak jet (right column, in unit of $\mathrm{ms}^{1}$ ). The top two panels show the spring mean TKE and shelfbreak jet velocity (across the Nantucket transect; positive means westward flow) averaged over 2004-2007. The following panels show the anomaly fields of TKE and shelfbreak jet in springs 2004 through 2007 relative to their respective 4-year means. Also shown in the left hand panels are 100 and $200 \mathrm{~m}$ isobaths (white curves) and location of Nantucket transect (black line).The mean $<\mathrm{u}>$ and anomaly u' alongshelf transport values are given in the right-hand panels.

waters in spring 2004 are ca. $0.5^{\circ} \mathrm{C}$ cooler and ca. 0.4 PSU saltier than their respective 4-year mean seasonal temperature and salinity fields. In comparison, the simulated shelf water is ca. $0.5^{\circ} \mathrm{C}$ warmer and ca. 0.3 PSU fresher in spring 2007. Such interannual variability in local hydrography may be in part traced back further upstream. For instance, fresh water runoff from major rivers (Penobscot River, St. Johns River, Kennebec River, Androscoggin River and Merrimack River) in the Gulf of Maine is generally larger in 2006-2007 than in 2003-2004 (USGS river gauge data, not shown). Conceptually, the presence of relatively denser (saltier and warmer) shelf waters in 2004 favors a bottom-advected plume (Chapman and Lentz, 1994; Yankovsky and Chapman, 1997), whereas the presence of relatively lighter (warmer and fresher) shelf water in 2007 favors a surface-advected plume near the shelfbreak. The 


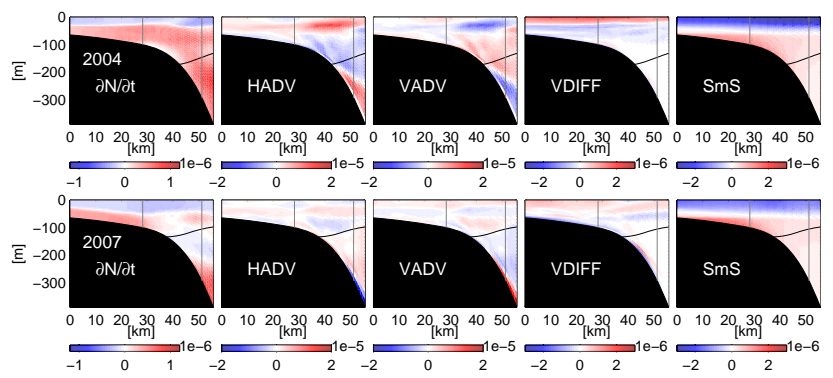

Fig. 13. Term-by-term diagnostic analysis of nutrient equation. Shown from left to right are the local rate of change $(\partial N / \partial t)$, horizontal advection (HADV), vertical advection (VADV), vertical diffusion (VDIFF), and biological source/sink (SmS) terms averaged over the early spring season (February-March-April) in year 2004 (top panels) and 2007 (bottom panels). The unit for all these terms is $(\mathrm{mmolN})\left(\mathrm{m}^{-3} \mathrm{~s}^{-1}\right)$. The 34.5 isohaline, which is commonly used to define the location of shelfbreak front (Linder and Gawarkiewicz, 1998; Chen and He, 2010), is also shown in each figure as black curve to indicate the position of the shelfbreak front. Two gray vertical lines indicate the locations of 100 and $300 \mathrm{~m}$ isobaths, between which the shelfbreak jet net nutrient budget terms are computed.

shelfbreak isopycnal tilting is steeper in the bottom-advected plume scenario, favoring a larger cross-shelf density gradient, and thus a stronger shelfbreak jet in 2004 than in 2007.

\subsection{Nutrient budget diagnostics}

The dynamic details of the nutrient field can be further analyzed through term-by-term diagnosis of its governing equation in the model:

$\frac{\partial N}{\partial t}=-\left(u \frac{\partial N}{\partial x}+v \frac{\partial N}{\partial y}\right)-w \frac{\partial N}{\partial z}+\frac{\partial}{\partial z}\left(K \frac{\partial N}{\partial z}\right)+$ hdiff + Source - Sink

By examining the relative importance of horizontal advection (HADV: $\left.-\left(u \frac{\partial N}{\partial x}+v \frac{\partial N}{\partial y}\right)\right)$, vertical advection (VADV: $-w \frac{\partial N}{\partial z}$ ), vertical diffusion (VDIFF: $\frac{\partial}{\partial z}\left(K \frac{\partial N}{\partial z}\right)$ ), horizontal diffusion (HDIFF), and source minus sink (SmS) terms for the local rate of change $(\partial N / \partial t)$, we seek to quantify key dynamic processes that dominate the shelfbreak nutrient balance.

For comparison, we perform such analysis for both 2004 and 2007, during the early spring season (Feb-Apr) when the shelfbreak jet is strongest (Linder et al., 2004; Chen and $\mathrm{He}, 2010)$. Figure 13 shows the seasonal averages of each term along the Nantucket transect for both years. The local rate of change $(\partial N / \partial t)$ terms in both years show the nutrient decreasing near the surface, reflecting nutrient uptake that exceeds supply to the upper water column.

The HADV term represents horizontal nutrient transport. We note that cross-shelf advection $-v \frac{\partial N}{\partial y}$ is smaller than along-shelf advection $-u \frac{\partial N}{\partial x}$ (not shown), so positive values of HADV mostly reflect along-shelf nutrient input from upstream, although at times cross-shelf advection can be significant. At the location of the shelfbreak jet, positive HADV (on the order of $10^{-5} \mathrm{mmol} \mathrm{N}\left(\mathrm{m}^{-3} \mathrm{~s}^{-1}\right)$ is seen near the surface in both springs, with values in 2004 much larger than in 2007. By definition, the along-shelf nutrient advection $-u \frac{\partial N}{\partial x}$ is affected by interannual variability in both nutrient concentration $(N)$ and shelfbreak jet $(u)$ strength. Both aspects contribute to the interannual variability in the simulated fluxes, as the jet is stronger and background nutrient concentrations are higher in spring 2004 versus spring 2007 (Figs. 7, 12). HADV also contains significant vertical structure. For example, seaward of the shelfbreak jet, negative HADV is seen at depth in both springs. This is probably related to the opposing slope current at depth (Fig. 12).

The shelfbreak break nutrient upwelling related to the secondary circulation and BBL convergence is represented by positive VADV values. We note that the model shows the mean vertical velocity at the shelfbreak is on the order of $10 \mathrm{~m}_{\text {day }^{-1}}$, a value comparable with the observation-based estimates (e.g., Houghton and Visbeck, 1998). In 2004, the positive VADV (on the order of $10^{-5} \mathrm{mmol} \mathrm{N} /\left(\mathrm{m}^{3} \mathrm{~s}^{-1}\right.$ ) at the shelfbreak extends from the foot of the shelfbreak front to the water column interior, and is significantly larger than the corresponding positive area of VADV in 2007, indicating nutrient upwelling due to the shelfbreak BBL convergence is stronger in 2004. Farther offshore (200 $\mathrm{m}$ and deeper), the shelf slope BBL VADV is larger in spring 2007 than in spring 2004. In general, HADV and VADV are one order of magnitude larger than other diagnostic terms. But because they are nearly mirror images of each other, the sum of HADV and VADV (i.e., the total advection) is the same order of magnitude as the diffusion term, SmS, and the local rate of change $(\partial N / \partial t)$.

The vertical diffusion term also shows significant contrast between 2004 and 2007. Larger positive VDIFF located in the surface in 2004 indicates stronger mixing that injects more nutrients to the upper water column, thereby providing a larger nutrient supply. It is interesting to note that the source minus sink (SmS) term representing biological processes is very similar in 2004 and 2007. This suggests the advection and diffusion processes play the major role in modifying the local rate of change of nutrient on interannual time scale. Finally, the source minus sink ( $\mathrm{SmS}$ ) shows opposite tendencies between the upper (negative) and lower (positive) part of the water column. Consistent with earlier studies (e.g., Hopkinson, 1987; Fennel et al., 2006), these patterns suggest nutrients are being utilized by phytoplankton near the surface, and are being regenerated at depth.

\section{Summary and conclusion}

We coupled an ecosystem model with an existing threedimensional high resolution circulation model (Chen and $\mathrm{He}$, 2010) for the MAB shelfbreak region. This coupled biophysical model is nested within an existing coupled ecosystem model (Lehmann et al., 2009) for the Middle Atlantic Bight 
and Gulf of Maine (MABGOM). The shelfbreak coupled biophysical model was used to hindcast the MAB shelfbreak circulation and ecosystem variations from December 2003 to November 2007. Favorable comparisons with MODISAQUA chlorophyll observations indicate that the coupled model can resolve the physical and biological dynamics at the MAB shelfbreak front. Time and space continuous hindcast fields from January 2004 to November 2007 were then used to investigate the seasonal and interannual characteristics of the MAB shelfbreak frontal circulation and ecosystem variability.

The existence of shelfbreak enhancement has been confirmed by synoptic observations (e.g., Marra et al., 1982; Ryan et al., 1999). Such a shelfbreak biomass enhancement is difficult to detect in the modeled mean field because it is not a permanent feature in the MAB region. Thus EOF analysis was used to highlight this variability. Consistent with previous studies (e.g., Marra et al., 1982, 1990; Ryan et al. , 1999a, 1999b; Gawarkiewicz et al., 2010), our model hindcast and EOF analysis suggest that there is a biomass enhancement at the shelfbreak. Region-wide upper water column nutrient content peaks in late winter and early spring. The phytoplankton spring bloom starts 1-2 months later, followed by a zooplankton bloom in early summer. Increased mixing in the fall season allows subsurface nutrient injection to the euphotic zone, stimulating a second but smaller phytoplankton bloom and subsequent zooplankton bloom.

Focusing on the early spring season (Feb-Apr), our analysis shows strong interannual variability of nutrient supply at the MAB shelfbreak. Specifically, the spring of 2004 and 2005 were relatively nutrient-rich, whereas the spring of 2006 and 2007 were relatively nutrient-poor. The cause for this feature has both atmospheric and oceanic origins. On one hand, stronger local wind mixing in winter and spring of 2004 and 2005 deepened the oceanic mixed layer depth up to $100 \mathrm{~m}$, making more deep-ocean nutrient available to the upper water column. On the other hand, the shelfbreak jet was stronger in spring 2004 and 2005, allowing more effective alongshore advection of nutrients from upstream. In addition to surface mixing and horizontal advection, vertical advection associated with the shelfbreak bottom boundary layer (BBL) convergence is another contributing factor for the upper water column nutrient content. This is confirmed by significant positive temporal correlation between the BBL convergence $\left(\nabla \cdot \boldsymbol{V}_{\text {bottom }}\right)$ and upper ocean nutrient content.

Nutrient budget diagnostics for spring 2004 and 2007 along the Nantucket transect highlighted not only complex vertical structures of various dynamical terms (processes), but also significant variations in magnitude between the two years. Because nutrient advection $(-u \partial N / \partial x-v \partial N / \partial y-$ $w \partial N / \partial z)$ is affected by interannual variability in both nutrient concentration $(N)$ and shelfbreak current $(u, v, w)$, it is difficult to distinguish the two effects in the present study, In the future, an idealized modeling investigation using the same nutrient background state $(N)$ will be pursued to further quantify the relative contributions of shelfbreak jet $(u)$ and local shelfbreak upwelling $(w)$ to the variation of shelfbreak nutrient content.

Although not analyzed explicitly in this study, interannual variability of the MAB shelfbreak circulation is also influenced by warm core rings. In summer 2006 for instance, a large warm core eddy impinged on the shelfbreak, slowing down the shelfbreak jet. Details of that process will be presented in a separate correspondence.

Our study demonstrates that realistic coupled biophysical modeling can offer a powerful tool to better understand and quantify complex physical and biological processes in an energetic shelfbreak environment. We note however that the complexity of the food web and uncertainties in parameterizations impose some limitations on coupled biophysical modeling. For example, the exclusion of the silicate compartment in our ecosystem model may reduce the accuracy of the simulated diatom population. Similarly, the coupled model overestimates chl-a in the winter season. The problem is likely due to deficiency in predicting mixing properties in the physical model. Another fact that accounts for the model-data discrepancies is that in reality, phytoplankton alter their chlorophyll content all the time in response to light and nutrient stress. Unlike satellite observations, our model does not have the functionality that can capture this kind of chlorophyll content variations. In this study, we focused on the seasonal and interannual variability. The natural step forward is to perform a detailed modeling study on the synoptic events as reported by Hales et al. (2009) and Bandstra et al. (2006). These observational studies provided useful ground-truth data for model calibration, validation and analysis on quasi-synoptic time scale.

Indeed, improvement in shelfbreak marine ecosystem prediction clearly requires refinement of model parameterizations, advanced observational infrastructure together with sophisticated techniques for data assimilation. In that regard, the emerging MAB shelfbreak Pioneer Array (a part of the Ocean Observatory Initiative from the National Science Foundation) and new in situ observations it is about to collect would be most valuable.

Acknowledgements. Research support provided through ONR Grant N00014-06-1-0739 and NASA Grant NNX07AF62G is much appreciated. We also thank Burke Hales of Oregon State University and two other anonymous reviewers for their very insightful review comments and suggestions.

Edited by: E. Boss 


\section{References}

Barth, J. A., Bogucki, D., Pierce, S. D., and Kosro, P. M.: Secondary circulation associated with a shelfbreak front, Geophys. Res. Lett., 25, 2761-2764, 1998.

Bandstra, L., Hales, B., and Takahashi, T.: High-frequency measurements of total CO2: Method development and first oceanographic observations, Mar. Chem., 100, 24-38, 2006.

Beardsley, R. C. and Flagg, C. N.: The water structure, mean currents, and shelf/slope water front on the New England continental shelf, Mem. Soc. R. Sci. Liege 6, 209-225, 1976.

Chapman, D. C.: A Simple Model of the Formation and Maintenance of the Shelf/Slope Front in the Middle Atlantic Bight, J. Phys. Oceanogr., 16, 1273-1279, 1986.

Chapman, D. C.: Boundary Layer Control of Buoyant Coastal Currents and the Establishment of a Shelfbreak Front, J. Phys. Oceanogr., 30, 2941-2955, 2000.

Chapman, D. C. and Beardsley, R. C.: On the origin of shelf water in the Middle Atlantic Bight, J. Phys. Oceanogr., 19, 384-391, 1989.

Chapman, D. C. and Lentz, S. J.: Trapping of a coastal density front by the bottom boundary layer, J. Phys. Oceanogr., 24, 14641479, 1994.

Chen, K. and He, R.: Numerical Investigation of the Middle Atlantic Bight Shelfbreak Frontal Circulation Using a Highresolution Ocean Hindcast Model, J. Phys. Oceanogr., 40, 949964, 2010.

Fairall, C. W., Bradley, E. F., Hare, J. E., Garchev, A. A., and Edson, J.: Bulk parameterization of air-sea fluxes: Updates and verification for the COARE algorithm, J. Clim., 16, 571-591, 2003.

Fennel, K., Wilkin, J., Levin, J., Moisan, J., O'Reilly, J., and Haidvogel, D.: Nitrogen cycling in the Middle Atlantic Bight: Results from a three-dimensional model and implications for the North Atlantic nitrogen budget, J. Geophys. Res., 111 (C06003), doi:10.1029/2005JC003116, 2006.

Fennel, K., Wilkin, J., Previdi, M., Najjar, R.: Denitrification effects on air-sea $\mathrm{CO}_{2}$ flux in the coastal ocean: Simulations for the Northwest North Atlantic, Geophys. Res. Lett., 35, L24608, doi:10.1029/2008GL036147, 2008.

Flather, R. A.: A tidal model of the northwest European continental shelf, Mem. Soc. R. Sci. Liege, 6(10), 141-164, 1976.

Gawarkiewicz, G. G. and Chapman, D. C.: The Role of Stratification in the Formation and Maintenance of Shelf-Break Fronts, J. Phys. Oceanogr., 22(7), 753-772, 1992.

Gawarkiewicz, G., Bahr, F., Beardsley, R. C., and Brink, K. H.: Interaction of a slope eddy with the shelfbreak front in the Middle Atlantic Bight, J. Phys. Oceangr., 31(9), 2783-2796, 2001.

Gawarkiewicz, G., Shcherbina, A., Charette, M., and Graziano, L.: Frontal Upwelling and Nutrient Transport in the Shelfbreak Front of the Middle Atlantic Bight, in review, 2010.

Geider, R., MacIntyre, H., and Kana, T.: A dynamic regulatory model of phytoplanktonic acclimation to light, nutrients, and temperature, Limnol. Oceanogr., 43, 679-694, 1998.

Haidvogel, D. B., Arango, H., Budgell, W. P., Cornuelle, B. D., Curchitser, E., Di Lorenzo, E., Fennel, K., Geyer, W. R., Hermann, A. J., Lanerolle, L., Levin, J., McWilliams, J. C., Miller, A. J., Moore, A. M., Powell, T. M., Shchepetkin, A. F., Sherwood, C. R., Signell, R. P., Warner, J. C., and Wilkin, J.: Ocean forecasting in terrain-following coordinates: Formulation and skill assessment of the Regional Ocean Modeling System, J. Comput.
Phys., 227, 7, 3595-3624, 2008.

Hales, B., Vaillancourt, R. D., Prieto, L., Marra, J., Houghton, R., and Hebert, D.: High-resolution surveys of the biogeochemistry of the New England shelfbreak front during summer, 2002, J. Marine Syst., 78, 426-441, 2009.

Harrison, W. G., Douglas, D., Falkowski, P., Rowe, G., and Vidal, J.: Summer nutrient dynamics of the Middle Atlantic Bight: nitrogen uptake and regeneration, J. Plankton Res., 5, 539-556, 1983.

He, R. and Wilkin, J. L.: Barotropic tides on the southeast New England shelf: A view from a hybrid data assimilative modeling approach, J. Geophys. Res., 111(C08002), doi:10.1029/2005JC003254, 2006.

He, R. and Chen, K.: Investigation of Northeastern North America Coastal Circulation Using a Regional Circulation Hindcast Model, Cont. Shelf Res., in review, 2008.

He, R., Chen, K., Moore, T., and Li, M.: Mesoscale variations of sea surface temperature and ocean color patterns at the MidAtlantic Bight shelfbreak, Geophys. Res. Lett., 37, L09607, doi:10.1029/2010GL042658, 2010.

Hopkinson, C. S.: Nutrient regeneration in shallow-water sediments of the estuarine plume region of the nearshore Georgia Bight, Mar. Biol., 94, 127-142, 1987.

Houghton, R. W.: Lagrangian flow at the foot of a shelfbreak front using a dye tracer injected into the bottom boundary layer, Geophys. Res. Lett., 24(16), 2305-2308, 1997.

Houghton, R. W. and Visbeck, M.: Upwelling and convergence in the Middle Atlantic Bight shelfbreak front, Geophys. Res. Lett., 25(15), 2765-2768, 1998.

Houghton, R. W., Schlitz, R., Beardsley, R. C., Butman, B., and Chamberlin, J. L.: The Middle Atlantic Bight cold pool: Evolution of the temperature structure during summer 1979, J. Phys. Oceanogr., 12, 1019-1029, 1982.

Houghton, R. W., Vaillancourt, R. D., Marra, J., Hebert, D., and Hales, B.: Cross-shelf circulation and phytoplankton distribution at the summertime New England shelfbreak front, J. Mar. Syst., 78(3), 411-425, 2009.

Lehmann, M. K., Fennel, K., and He, R.: Statistical validation of a 3-D bio-physical model of the western North Atlantic, Biogeosciences, 6, 1961-1974, doi:10.5194/bg-6-1961-2009, 2009.

Lentz, S.: Observations and a model of the mean circulation of the Middle Atlantic Bight Continental shelf, J. Phys. Oceanogr., 38, 1203-1221, 2008.

Lima, I. D. and Doney, S. C.: A three-dimensional, multinutrient, and size-structured ecosystem model for the North Atlantic, Global Biogeochem. Cy., 18(GB3019), doi:10.1029/2003GB002146, 2004.

Linder, C. A. and Gawarkiewicz, G.: A climatology of the shelfbreak front in the Middle Atlantic Bight, J. Geophys. Res.Oceans, 103, 18405-18424, 1998.

Linder, C. A., Gawarkiewicz, G. G., and Pickart, R. S.: Seasonal characteristics of bottom boundary layer detachment at the shelfbreak front in the Middle Atlantic Bight, J. Geophys. Res., 109(C03049), doi:10.1029/2003JC002032, 2004.

Lorder, J. W., Petrie, B., and Gawarkiewicz, G.: The coastal ocean off northeastern North America: A large-scale view, in The Sea, 105-133, Wiley, New York, 1998. 
Luettich, R. A., Westerink, J. J., and Scheffner, N. W.: ADCIRC: An advanced three-dimensional circulation model for shelves, coast, and estuaries, Report 1. Theory and Methodology of ADCIRC-2DDI and ADCIRC-3DL., US Army Corps of Engineers Tech. Rep., DPR-92-6, 137 pp, 1992.

Marchesiello, P., McWilliams, J. C., and Shchepetkin, A. F.: Open boundary conditions for long-term integration of regional oceanic models, Ocean Model., 3, 1-20, 2001.

Marra, J., Houghton, R. W., Boardman, D. C., and Neale, P. J.: Variability in surface chlorophyll at a shelfbreak front, J. Mar. Res., 40(3), 575-591, 1982.

Marra, J., Houghton, R. W., and Christopher, G.: Phytoplankton growth at the shelf-break front in the Middle Atlantic Bight, J. Mar. Res., 48(4), 851-868, 1990.

Mellor, G. L. and Yamada, T.: Development of a Turbulence Closure Model for Geophysical Fluid Problems, Rev. Geophys. Space GE, 20, 851-875, 1982.

Miles, T. N., He, R., and Li, M.: Characterizing the South Atlantic Bight seasonal variability and cold water event in 2003 using a daily cloud free SST and chlorophyll analysis, Geophys. Res. Lett., 36(L02604), doi:10.1029/2008GL036396, 2009.

O'Reilly, J. E. and Zetlin, C.: Seasonal, horizontal, and vertical distribution of phytoplankton chlorophyll a in the northeast US continental shelf ecosystem, in NOAA Technical Report NMFS, 139 pp., US Department of Commerce, 1998.

Pickart, R. S.: Bottom boundary layer structure and detachment in the shelfbreak jet of the Middle Atlantic Bight, J. Phys. Oceanogr., 30, 2668-2686, 2000.

Podestá, G. P., Browder, J. A., and Hoey, J. J.: Exploring the association between swordfish catch rates and thermal fronts on U.S. longline grounds in the western North Atlantic, Cont. Shelf Res., 13, 253-277, 1993.

Rowe, G. T., Clifford, C. H., Smith, K. L., and Hamilton, P. L.: Benthic nutrient regeneration and its coupling to primary productivity in coastal waters, Nature, 255, 215-217, 1975.

Rowe, G. T., Clifford, C. H., and Smith, K. L.: Nutrient regeneration in sediment off Cape Blanc, Spanish Sahara, Deep-Sea Res. Pt.I, 24, 57-63, 1977.

Ryan, J. P., Yorder, J. A., Barth, J. A., and Cornillon, P. C.: Chlorophyll enhancement and mixing associated with meanders of the shelf break front in the Mid-Atlantic Bight, J. Geophys. Res., 104(C10), 23479-23493, 1999a.
Ryan, J. P., Yorder, J. A., and Cornillon, P. C.: Enhanced chlorophyll at the shelfbreak of Mid-Atlantic Bight and Georges Bank during the spring transition, Limnol. Oceanogr., 44(1), 1-11, 1999b.

Ryan, J. P., Yorder, J. A., and Townsend, D. W.: Influence of a Gulf Stream warm-core ring on water mass and chlorophyll distributions along the southern flank of Georges Bank, Deep-Sea Res. Pt. 2, 48, 159-178, 2001.

Shchepetkin, A. F. and McWilliams, J. C.: The regional oceanic modeling system (ROMS): a split-explicit, free surface, topography-following-coordinate oceanic model, Ocean Model., 9, 347-404, 2005.

Sosik, H. M., Green, , R. E., Pegan, W. S., and Roesler, C. S.: Temporal and vertical variability in optical properties of New England shelf waters during late summer and spring, J. Geophys. Res., 106, 9455-9472, 2001.

Taylor, K. E.: Summarizing multiple aspects of model performance in a single diagram, J. Geophys. Res.-Atmos., 106, 7183-7192, 2001.

Townsend, D. W. and Thomas, M.: Springtime nutrient and phytoplankton dynamics on Georges Bank, Mar. Ecol.-Prog. Ser., 228, 54-74, 2002.

Walsh, J. J., Whitledge, T. E., O'Reilly, J. E., Phoel, W. C., and Draxler, A. F.: Nitrogen cycling on Georges Bank and the New York Shelf: A comparison between well-mixed and seasonally stratified waters, in: Georges Bank, edited by: Backus, R. H. and Bourne, D. W., 234-246, The MIT Press, 1987.

Waring, G. T., Hamzaki, T., Sheehan, D., Wood, G., and Baker, S.: Characterization of Beaked Whale (Ziphiidae) and Sperm Whale (Physeter Macrocephalus) summer habitat in shelf-edge and deeper waters off the northeast U.S., Mar. Mammal Sci., 17, 703-717, 2001.

Yankovsky, A. E. and Chapman, D. C.: A Simple Theory for the Fate of Buoyant Coastal Discharges, J. Phys. Oceanogr., 27, 1386-1401, 1997.

Yorder, J. A., Schollaert, S. E., and O'Reilly, J. E.: Climatological phytoplankton chlorophyll and sea surface temperature patterns in continental shelf and slope waters off the northeast U.S. coast, Limnol. Oceanogr., 47, 672-682, 2002. 